\title{
Division of the Physics of Condensed Matter
}

\author{
S. F. Edwards \\ Chairman of the Division
}

The Division came into existence at the meeting of the EPS Council in July 1969. An ad hoc committee had been in existence before this date which helped the EPS in the organization of a section of the Inaugural Conference of the European Physical Society at Florence, and presented views to the Council as to how the Division could be organized. As with the other Divisions, the present organization is provisional, and has two years in which to prove its worth.

"Condensed Matter" is a very large but closely interlinked field. It was therefore decided that, at least during this initial period, its Board would be nominated by the National Societies. This has been done and the Board has begun work on its main tasks. In order to cover their region of physics adequately the Board is organizing a series of European subject groups. Those so far formed are in Metals (with A.R. Mackintosh of Copenhagen as Chairman), Insulators and SemiConductors (O. Madelung, Marburg) and Magnetism (E.P. Wohlfarth, London). There already existed in Europe an active Group for the study of the physics of high pressures, and the Division is pleased to announce that this group will become associated with the EPS, the Chairman being D. François, Montrouge. Other groups are being formed, but the number is being kept small since, in a general discussion on this kind of structure at the EPS Council meeting in Paris, it was felt that too much fragmentation of subjects was to be avoided. It is hoped that the formation of the groups will be completed by the end of this year and the Division will then be able to claim to be a comprehensive and truly European organization fully able to advise EPS in its area, and to carry out the tasks assigned to it.

\section{Work of the Division}

It is natural that, at this early stage, the Division has been mainly concerned with Conferences. It has seemed to many physicists in Europe that two features of conferences in the United States could and should have a counterpart in Europe: the Gordon Conferences, and the Solid State Meetings of the American Physical Society. The Gordon Conferences are basically small (about a hundred participants) invitation conferences going into a topic in real depth. Similar meetings have been started in Europe and the EPS has undertaken to give these conferences a central organization under the title of Europhysics Conference (see Europhysics News No. 7, and the Meetings section of this issue for examples). Such meetings need continuity and stimulation. The Division plans the continuation of a series of these meetings in its area and, with its groups, it presents plans to the EPS Conference Committee. The fact that the EPS is stimulating such meetings should not, of course, deter people from either bringing suggestions forward, or from offering to organize meetings.

The American Physical Society holds a big meeting once a year with a large (thousands of participants) attendance covering the whole area of Solid State Physics. Should such meetings be held in Europe? After asking for opinions, the Board came to the opinion that a large meeting would be very valuable, but that a two year frequency would be correct, at least at first, and that the meeting should have a more definite orientation than the APS meeting. The forthcoming meeting is described below. This decision was reached with the feeling that the large annual national meetings held at present could not be amalgamated, since the high cost of travel in Europe would mean that research students and young research workers would be cut off from such an annual review of the field. Nevertheless, there should be an opportunity for condensed matter physicists to get together on a European basis in a meeting of the structure outlined below.

\section{Forthcoming Meeting in Florence}

The Division has received, and accepted, a generous offer from Italy to hold its Divisional Conference in
Florence at the Palazzo dei Congressi, on 14-17 September 1971. It has been decided to base the conference on two themes: a particular region of condensed matter, and a general phenomenon. The choice has been of metals, and of phase changes. It is hoped to give a comprehensive survey of the latest developments in meta physics both in electronic properties and structure. With phase changes there will be accounts of the latest developments in critical phenomena, and special attention will be paid to the richness of this subject in many unusual fields. The conference will have invited and contributed papers. Its final form is being worked out and a full announcement will be made later.

\section{Outlook}

The Board of the Division hopes for a large attendance at the Florence meeting, not only for scientific reasons, but also for the opportunity it will give to consult people as to what they want the Division (and indeed the EPS) to do in the future. This leads to a general remark addressed to all workers in condensed matter in Europe. It is inevitable that the progress of the Division reflects the opinions of a very small number of people. Those with opinions as to what the Division should be doing, should therefore not hesitate to write to any member of the Board. Such opinions will be fully considered and discussed. The present members of the Board are:

S.F. Edwards, Manchester (Chairman)

A.B. Lidiard, Harwell (Secretary)

S. Akpinar, Ankara

V. Bezak, Bratislava

G. Boato, Genoa

A. Corciovei, Bucharest

G. de Vries, Amsterdam

J. Diehl, Stuttgart

A. Guinier, Paris

S. Lundqvist, Goteborg

A. Many, Rehovoth

W. Merz, Zurich

H.J.G. Meyer, Eindhoven

Ju.A. Osityan, Moscow

G. Szigeti, Budapest

L. van Gerven, Heverlee 